\title{
PENGEMBANGAN PLATFORM "NOBEL GADDE2 NA" SEBAGAI PERWUJUDAN ACADEMIC ENTREPRENEURSHIP PADA INKUBATOR BISNIS STIE NOBEL INDONESIA
}

\author{
Agunawan $^{1}$, Hasanah Nur ${ }^{2}$, Ahmad Firman $^{3}$ \\ STIE Nobel Indonesia Makassar \\ Email : agunawan108@gmail.com¹, hasanah@unm.ac.id²,a_firman25@yahoo.com³
}

\begin{abstract}
ABSTRAK
Ketersediaan tenaga kerja terampil yang dibutuhkan Dunia Usaha dan Kerja (DUKA) masih sangat rendah. Hal ini terungkap dari data Badan Pusat Statistik (BPS) yang diumumkan pada Bulan Februari 2020 yakni sekitar 13\%. Kondisi ini merupakan tantangan bagi perguruan tinggi untuk tidak memperparah kondisi ini dengan menperkenalkan suasana kerja lebih dini kepada mahasiswa, agar dapat menjadi lulusan sesuai kebutuhan pasar kerja, baik sebagai karyawan ataupun pemilik usaha melalui inkubator bisnis mahasiswa. Inkubator Bisnis merupakan salah satu bentuk Academic Entrepreneurship yang disesuaikan dalam era industri 4.0 yang berbasis pada pemanfaatan media elektronik dan internet. Teknik pengumpulan data berupa wawancara dengan pemangku kepentingan (mahasiswa, unit usaha Nobel dan pengelola inkubator) yang dideksripsikan serta studi literatur dan aplikasi. Platform "Nobel Gadde2 Na" merupakan aplikasi yang dibuat mengikuti metode Research and Development (R\&D) dengan mengadopsi Model Waterfall Pressman dan Borg \& Gall. Model ini direkonstruksi sesuai kebutuhan inkubator bisnis yang disebut Sintesis Model. Desain pemodelan dalam bentuk diagram konteks dan pengembangan aplikasi menggunakan Wordpress dengan database MySQL. Aplikasi ini diharapkan dapat menjadi sarana pengelolaan usaha mahasiswa khususnya dan unit usaha STIE Nobel Indonesia pada umumnya, serta mitra usaha di sekitar kampus agar dikenal lebih luas. Dan nantinya dapat membentuk sebuah Academic Entrepreneurship melalui Inkubator Bisnis berbasis teknologi informasi dan komputer.
\end{abstract}

Kata Kunci: Bisnis, Gadde, Inkubator, Kewirausahaan, Nobel.

\section{ABSTRACT}

The availability of skilled workers needed in the Business and Work World (DUKA) is remain very low. This is revealed from data from the Central Statistics Agency (BPS) announced in February 2020 of about 13\%. This condition is a challenge for universities not to aggravate this condition by introduce an early working atmosphere to students, in order to become graduates according to the needs of the job market, either as employees or business owners through student business incubators. Business Incubator is a form of Academic Entrepreneurship that is adapted in the industrial era 4.0 based on the utilization of electronic media and the internet. Data collection techniques in the form of interviews with stakeholders (students, Nobels business units and incubator managers) are described as well as literature and application studies. The "Nobel Gadde $2 \mathrm{Na}$ " platform is an application made following the Research and Development $(R \& D)$ method by adopting the Waterfall Pressman and Borg \& Gall models. This model is reconstructed according to the needs of a 
business incubator called Model Synthesis. Design modeling in the form of context diagrams and application development using WordPress with MySQL databases. This application is expected to be a means of managing student businesses in particular and business units of STIE Nobel Indonesia in general, as well as business partners around the campus to be known more widely. And later can form an Academic Entrepreneurship through a Business Incubator based on information technology and computers.

Keywords: Business, Entrepreneurship, Incubator, Marketplace, Nobel

\section{PENDAHULUAN}

Laporan Badan Pusat Statistik (BPS) Bulan Februari 2020 seperti yang kutip di Kompas (Media, 2020) bahwa dari 131,03 juta total tenaga kerja di Indonesia, 38,9\% merupakan lulusan Sekolah Dasar, Sekolah Menengah Pertama 17,93\%, Sekolah Menengah Atas 18,34\%, Sekolah Menengah Kejuruan $11,82 \%$ dan Perguruan Tinggi $13,02 \%$. Ini berarti bahwa Indonesia masih kekurangan tenaga kerja yang terampil sesuai dengan kebutuhan pasar kerja. Data ini menunjukkan adanya ketimpangan keseimbangan tenaga kerja yang terserap di lapangan kerja Indonesia. Jumlah tenaga kerja dengan pendidikan lebih rendah dengan kemampuan terbatas jauh lebih besar dari berpendidikan lebih tinggi sementara kebutuhan tenaga terampil kian meningkat setiap tahunnya. McKinsey Global Institute (MGI) mengolah data BPS 2016 dalam (Media, 2020), mengatakan bahwa Indonesia berpotensi menjadi negara ke-7 dunia di tahun 2030 berdasarkan tingkat ekonominya.

Untuk menghilangkan kesenjangan tersebut, pemerintah Indonesia telah membuat beberapa kebijakan terkait penciptaan tenaga kerja yang unggul. Sebagaimana diuraikan Dirjen Pendidikan Vokasi pada Kompas (Media, 2020) yaitu program Link and Match. Langkah ini dilanjutkan dengan program-program seperti, melibatkan mahasiswa berwirausaha lebih dini, dan bekerjasama dengan industri dalam merancang kurikulum terkait kewirausahaan. Dalam kurikulum ini, Dunia Usaha dan Kerja (DUKA) duduk bersama dengan perguruan tinggi dalam merumuskan kurikulum agar sesuai dengan kebutuhan pasar kerja.

Di STIE Nobel sendiri, tingkat pengangguran bagi lulusan tergolong rendah. Hal ini disebabkan sistem pendidikan yang mewajibkan semua mahasiswa/i memiliki usaha sebelum dinyatakan lulus (prasyarat). Tapi setelah mereka dilepas (wisuda), apakah alumni tetap meneruskan usaha tersebut atau tidak, atau sekedar pemenuhan syarat kelulusan.

Platform "Nobel Gadde2 Na" memastikan keberlanjutan usaha tersebut yang dilihat melalui transaksi karena terdapat bagi hasil keuntungan dengan pengelola inkubator bisnis. Inkubator bisnis sendiri membekali mereka kemampuan berwirausaha yang sudah menghasilkan sebelum lulus. Dan sebagai bentuk pengabdian masyarakat di sekitar kampus, dibentuk kemitraan sebagai ajang promosi usaha mereka melalui aplikasi ini. Dengan terwujudnya semua unsur ini, akan terbentuklah yang disebut kewirausahaan perguruan tinggi (Academic Entrepreneurship). 


\section{LANDASAN TEORI}

2.1 Kajian Teori

Academic Entrepreneurship atau kewirausahaan akademis seperti dikutip pada (B. Urban, 2019) dinarasikan sebagai perusahaan baru yang dimulai dalam lingkungan kampus dan teknologi yang berasal dari penelitian perguruan tinggi. Rancangan kurikulum yang disesuaikan kebutuhan pasar kerja pada mata kuliah kewirausahaan merupakan upaya dalam mewujudkan kewirausahaan akademis.

Jadi kewirausahaan akademis merupakan upaya-upaya yang dilakukan oleh perguruan tinggi untuk menumbuhkan usaha-usaha yang melibatkan mahasiswa, dosen dan institusi. Tujuan utamanya pada penerapan ilmu pengetahuan yang didapatkan dalam pembelajaran dan ada konsekuensi ekonomi di dalamnya.

Inkubator Bisnis STIE Nobel Indonesia Makassar adalah turunan dari model pembelajaran kewirausahaan yang dikelola oleh Direktorat Perusahaan Pemula Berbasis Teknologi pada Kementerian Riset, Teknologi, dan Pendidikan Tinggi yaitu Inkubator Bisnis Teknologi (IBT) (Ristekbrin, 2018). Perwujudan dari program ini berbentuk instrumen kegiatan yang terdiri pendanaan, pelatihan, dan pendampingan bagi inkubator dan tenant (startup) yang dilaksanakan dalam sebuah kompetisi.

Inkubator Bisnis STIE Nobel sendiri mengadopsi tujuan dan pendekatan yang digunakan dari program pemerintah tersebut. Hal-hal yang terkait pendanaan, pelatihan dan pembimbingan dilakukan secara mandiri dalam bingkai sistem pembelajaran berbasis proyek. Luaran dari proyek ini adalah sebuah unit usaha baru yang berbadan hukum.

Menurut Hewick (2006) dalam (Ardiansyah et al., 2019), inkubator adalah sarana yang disiapkan oleh perguruan tinggi sebagai bentuk dukungan terciptanya mahasiswa berwirausaha yang memenuhi syarat berupa: workshop, pendampingan, jaringan usaha, bantuan akses pemodalan sampai mereka berhasil dan menciptakan usaha baru. Jadi Inkubator Bisnis STIE Nobel Indonesia Makassar merupakan suatu wadah di dalam kampus yang menyediakan fasilitas dan berperan sebagai katalisator dalam untuk mempercepat terwujudnya kewirausahaan mahasiswa. Hal ini sejalan dengan Peraturan Presiden 27/2013 tentang Pengembangan Inkubator Wirausaha dan Permenkop dan UKM No. 24/2015 terkait Norma, Standar, Prosedur, dan Kriteria dalam Inkubator Wirausaha.

Sebagai perguruan tinggi yang berbasis pada kewirausahaan, STIE Nobel Indonesia Makassar menyusun kurikulum untuk mempersiapkan lulusan menjadi bagian dalam perekonomian Indonesia. Pembentukan karakter dan jiwa entrepreneurship sudah dibangun sejak awal perkuliahan, meliputi (1) memasukkan unsur-unsur kewirausahaan di setiap mata kuliah terutama terkait kompetensi; (2) kurikulum berbasis masalah atau proyek; (3) menghadirkan kerja nyata di kampus melalui teaching factory; (4) konsultasi bisnis; (5) mewajibkan mahasiswa dengan tenant di beberapa event; (6) dan sistem magang berjenjang. (Fitriany et al., 2019)

Untuk mewujudkan kewirausahaan akademis pada inkubator bisnis STIE Nobel Indonesia, maka dikembangkan 
platform "Nobel Gadde2 Na" untuk memperkenalkan usaha dan produk/jasa yang dikembangkan mahasiswa yang berbasis e-commerce. Nama platform, "Nobel" merujuk pada nama lembaga dan "Gadde2 Na" merujuk bahasa lokal (Bugis-Makassar) yang bermakna usaha atau produk jualan.

\subsection{Penelitian Terdahulu}

(Ardiansyah et al., 2019) mengemukakan bahwa inkubator bisnis merupakan upaya menumbuhkan jiwa entrepreneurship mahasiswa berupa pelatihan, pembinaan dan membuat usaha baru dan sekaligus penerapan mata kuliah kewirausahaan. Penelitian ini lebih fokus pada peranan inkubator bisnis sebagai sistem penciptaan kewirausahaan mahasiswa sebagai sebuah bisnis startup.

Menurut (Lutfiani et al., 2020), dengan adanya inkubator bisnis, kinerja perguruan tinggi dapat dilihat dalam pengembangan startup terkait dengan pengabdian masyarakat sebagai salah satu wujud dari tridharma perguruan tinggi. Penelitian ini menyoroti peran inkubator bisnis dalam memberi dampak positif yang didapatkan perguruan tinggi terutama dalam penerapan tridarma perguruan tinggi.

(Abidah et al., 2020), mengemukakan bahwa untuk dapat bertahan di era industri 4.0, usaha perlu berubah ke sistem digital termasuk inkubator bisnis yang ada di perguruan tinggi. Penelitian ini membuat model platform digital berbasis ecommerce dengan model triple helix yaitu melibatkan perguruan tinggi sebagai pengelola, pemerintah dengan fasilitas dan dunia industri atau usaha kecil menengah sebagai pengguna.
Penelitian ini sendiri, membahas inkubator bisnis yang sudah berjalan di STIE Nobel Indonesia dengan penambahan platform sebagai sistem informasi yang pengelolaan usaha mahasiswa/i maupun alumni, usaha nobel sendiri dan mitra sebagai bentuk pengabdian masyarakat.

\section{METODE PENELITIAN}

Penelitian ini berlokasi di STIE Nobel Indonesia Makassar dan menggunakan Metode Research and Development (R\&D). (Sugiyono, 2012) menulisnya sebagai metode yang luarannya berupa sebuah produk tertentu, dan dilakukan pengujian terhadap efektifitasnya. (Dr. Budiyono Saputro, M.Pd., 2017) menyimpulkan sebagai metode yang luarannya sebuah produk pada bidang keahlian tertentu dengan produk sampingan yang efektif. Jadi, metode penelitian dan pengembangan adalah proses untuk menghasilkan sebuah luaran yang teruji secara ilmiah.

Teknik pengumpulan data berupa wawancara, data diolah dan dideskripsikan untuk kebutuhan sistem yang dikembangkan. Studi literatur untuk memperkuat kajian konsep dan studi aplikasi. Desain pemodelan untuk menggambarkan sistem secara keseluruhan dalam bentuk diagram konteks.

Pengembangan platform dengan Content Management System (CMS) Wordpress dan MySQL sebagai databasenya. Dan pengujian dilakukan pada interaksi pengguna dan aplikasi melalui desain antar muka, baik dengan PC/laptop maupun gadget.

Platform "Nobel Gadde2 Na" merupakan aplikasi (perangkat lunak) sehingga pendekatan yang digunakan 
mengadopsi Model Waterfall. Model Waterfall (Roger S. Pressman, 2010) merupakan model klasik dengan tahapan yang sistematis dan berurutan, meliputi (1) requirement; (2) design; implementation; (4) verification; dan (5) maintenance. Tahapan tersebut direkonstruksi dengan model (Borg and Gall, 1983) yang disesuaikan dengan kebutuhan aplikasi yang dikembangkan dan disebut sebagai Sintesis Model (Agunawan, 2020) seperti pada gambar berikut:

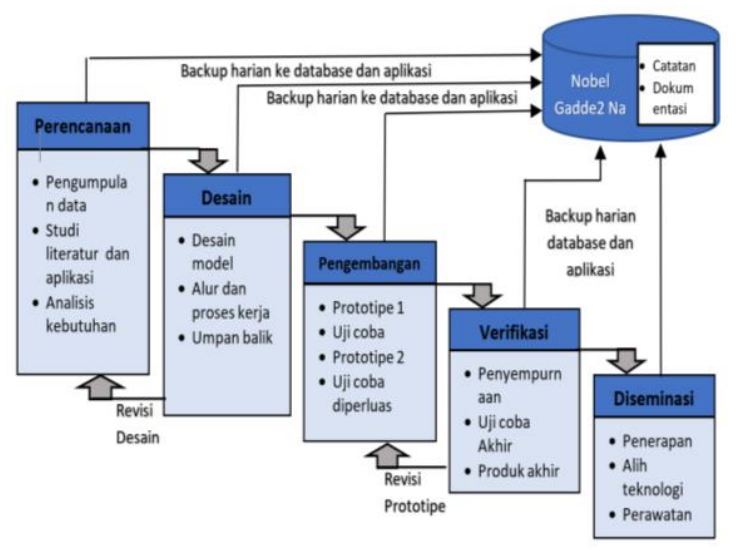

Gambar 1. Sintesis Model Pengembangan

\section{HASIL DAN PEMBAHASAN}

Mengacu pada model pengembangan tersebut, berikut uraiannya:

\subsection{Perencanaan}

a. Pengumpulan data; dengan wawancara kepada pemangku kepentingan yaitu mahasiswa/i, dosen, pengelola unit usaha Nobel dan inkubator bisnis serta mitra usaha di sekitar kampus. Terkait cakupan inkubator bisnis dan usaha, promosi, pemasaran produk, transaksi, bagi hasil dan visi ke depannya.

b. Studi literatur dan aplikasi; untuk mendapatkan kajian teori dari aplikasi yang akan dibuat terkait dengan inkubator bisnis mahasiswa/i dalam kewirausahaan akademik untuk memperkuat kajian konsep, termasuk mengidentifikasi permasalahan. Studi aplikasi, dengan melakukan serangkaian uji coba terhadap aplikasi marketplace seperti Bukalapak, Shopee dan penjualan langsung via media sosial, untuk melihat fitur-fiturnya, alur kerja dan proses yang dapat diadopsi pada Platform "Nobel Gadde2 $\mathrm{Na}$.

c. Analisis kebutuhan; merupakan analisis data yang didapatkan terkait alur dan kerangka kerja sistem dan platform yang dikembangkan. Penentuan parameter dan variabel yang digunakan sekaligus memastikan bahwa sistem yang dibuat sesuai dengan kebutuhan.

\subsection{Desain}

Pada tahap ini dilakukan desain awal model yang diusulkan, alur dan proses kerja dari aplikasi yang akan dikembangkan. Fase ini didiskusikan dengan pemangku kepentingan terhadap rancangan desain dan alur. Jika belum ditemukan titik temu, proses dapat kembali ke tahap perencanaan. Tabel berikut menyajikan fase ini.

Tabel 1. Desain dan Alur Model

\begin{tabular}{|l|l|}
\hline Desain & Uraian \\
\hline Spesifikasi & Kerangka dasar model \\
\hline Arsitektur & $\begin{array}{l}\text { Penjabaran hardware dan } \\
\text { software }\end{array}$ \\
\hline $\begin{array}{l}\text { Database / } \\
\text { Backend }\end{array}$ & $\begin{array}{l}\text { Jenis, type, field, RDBMS } \\
\text { dan variabel }\end{array}$ \\
\hline $\begin{array}{l}\text { Interface/ } \\
\text { Frontend }\end{array}$ & $\begin{array}{l}\text { Interaksi antara aplikasi } \\
\text { dan pengguna }\end{array}$ \\
\hline Script/coding & $\begin{array}{l}\text { Bahasa pemrograman atau } \\
\text { CMS yang digunakan }\end{array}$ \\
\hline
\end{tabular}

Sumber: data diolah 


\subsection{Pengembangan}

Merupakan tahapan pengembangan aplikasi yang mencakup bagaimana aplikasi ini bekerja, struktur database, dan aliran antar entitas yang efektif dalam kerangka logikal dan sesuai yang dibutuhkan. Merupakan implementasi konsep desain yang dibuat ke dalam bentuk bahasa yang dimengerti oleh mesin (pemrograman), desain antar muka, penyimpanan data yang menjadi standar sistem. Pada fase ini juga dilakukan uji coba terbatas di lingkup pengelola inkubator bisnis, untuk memastikan sistem berjalan sesuai alur logika dan sesuai dengan target yang diinginkan.

Untuk melihat alur dan proses kerja dari platform ini secara keseluruhan, dapat dilihat pada diagram konteks pada gambar berikut:

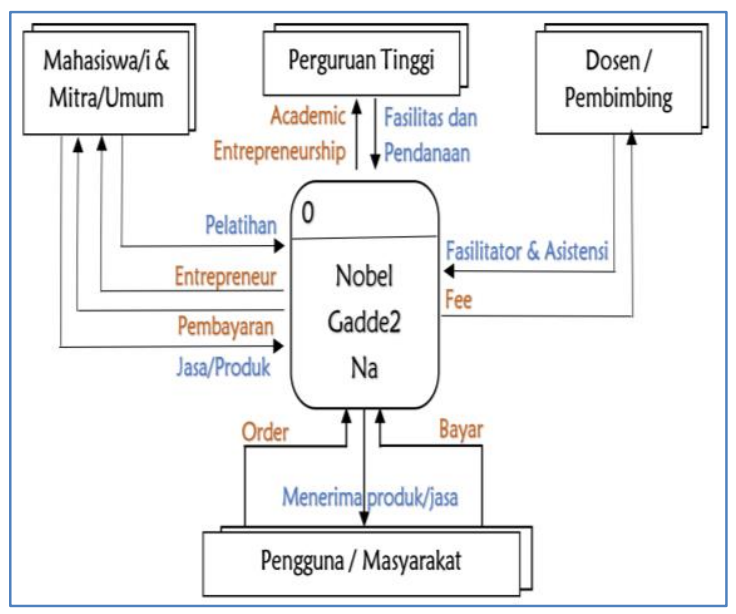

Gambar 2. Diagram Konteks

Pengujian awal merupakan upaya untuk memastikan bahwa aplikasi tersebut telah sesuai dengan peruntukannya termasuk fitur-fitur didalamnya sudah terpenuhi. Calon pengguna dilibatkan pada tahap ini dalam upaya melacak kekurangan-kekurangan yang ada dan memberikan umpan balik.

\subsection{Verifikasi}

Tahap selanjutnya adalah penyermpurnaan produk yang dianggap sebagai final pengembangan. Tahapan ini meliputi hal berikut:

\subsubsection{Desain Antar Muka}

Merupakan tampilan awal disaat pengguna mengakses platform ini melalui internet dan dapat diakses melalui komputer/laptop maupun gadget (smartphone atau tablet).

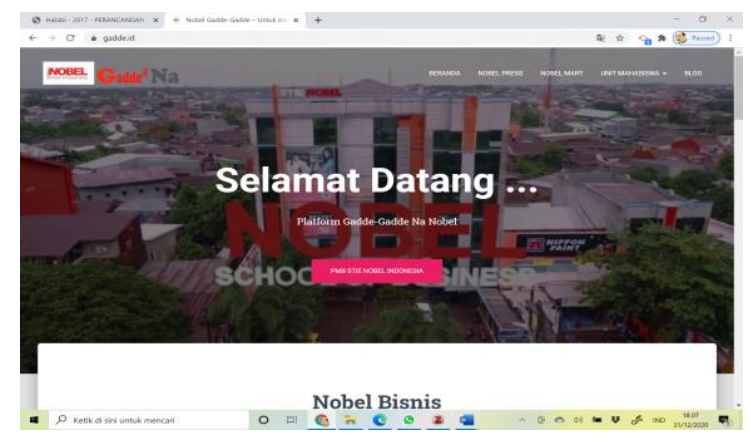

Gambar 3. Beranda Nobel Gadde2 Na

Bagian ini menyajikan informasi terkait inkubator bisnis, pengelola dan hal lain mengenai STIE Nobel Indonesia dan juga link ke website resmi dan jaringan usaha lainnya. Bagian menu terdapat pilihan inkubator bisnis yang dikelola langsung kampus dan usaha-usaha yang dikembangkan mahasiswa/i. Sebagai bentuk pengabdian masyarakat, inkubator bisnis ini bermitra dengan usaha-usaha masyarakat (binaan) yang ada di sekitar kampus.

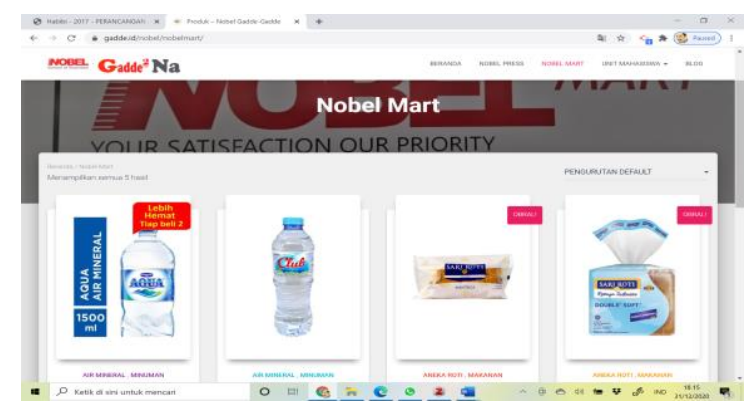

Gambar 4. Unit Usaha Nobel 
Merupakan minimarket yang dikelola oleh unit usaha kampus, melayani penjualan secara langsung dan online. Sistem pembayaran Cash on Delivery (bayar di tempat) atau transfer ke rekening. Barang diantar langsung petugas atau menggunakan jasa antar online (terdapat tambahan biaya pengiriman). Untuk kedepannya akan bekerjasama dengan GoJek melalui GoPay.

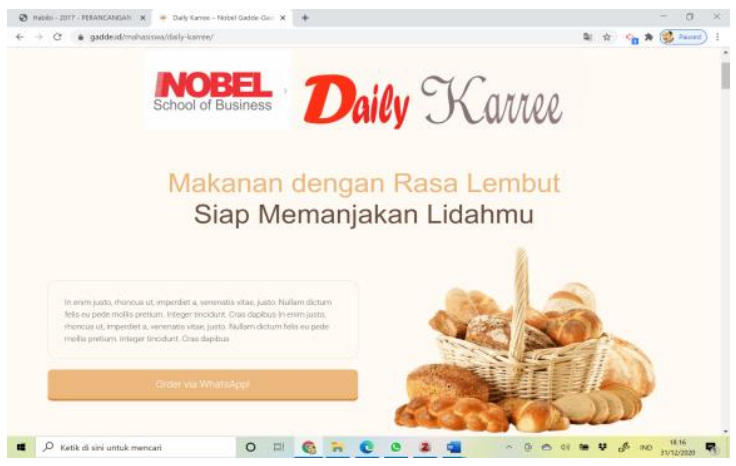

Gambar 5. Unit Usaha Mahasiswa

Salah satu unit usaha dalam inkubator bisnis mahasiswa. Setiap mahasiswa/i yang dianggap memenuhi syarat dalam inkubator bisnis, akan dibuatkan landingpage yang terhubung di Platform "Nobel Gadde2 Na", dimana transaksinya langsung terkoneksi ke No. WhatsApp pemilik usaha (mahasiswa/i). Mekanisme transaksi diputuskan melalui pemilik usaha dan pelanggan. Platform hanya mencatat transaksi sebagai dasar bagi hasil antara dengan pengelola.

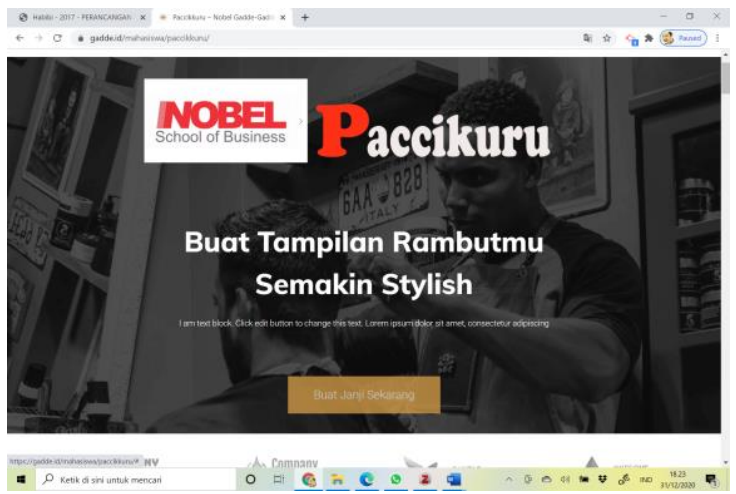

Gambar 6. Unit Usaha Mitra
Mekanisme kerja sama dengan usaha mahasiswa/i, yang membedakan pada pemilik usaha adalah mitra kerjasama dengan usaha masyarakat sekitar kampus dan perhitungan bagi hasil berbeda.

\subsubsection{Pengujian Platform}

Pengujian Platform "Nobel Gadde2 $\mathrm{Na}$ " secara luas dilakukan untuk memastikan bahwa perbaikan-perbaikan berarti (signifikan) telah diselesaikan sampai aplikasi dianggap siap untuk diterapkan. Jika dianggap perlu tahapan bisa kembali ke fase pengembangan.

Hal-hal yang diuji tersaji pada tabel berikut:

Tabel 2. Pengujian Platform

\begin{tabular}{|c|c|}
\hline Pengujian & Indikator \\
\hline \multicolumn{2}{|l|}{ Menu Utama } \\
\hline Beranda & $\sqrt{ }$ \\
\hline Berita & $\sqrt{ }$ \\
\hline Kontak & $\sqrt{ }$ \\
\hline \multicolumn{2}{|c|}{ Unit Usaha Nobel } \\
\hline Aksebilitas & $\sqrt{ }$ \\
\hline Konten & $\sqrt{ }$ \\
\hline Transaksi & $\sqrt{ }$ \\
\hline \multicolumn{2}{|c|}{ Unit Usaha Mahasiswa/i } \\
\hline Aksebilitas & $\sqrt{ }$ \\
\hline Konten & $\sqrt{ }$ \\
\hline Transaksi & $\sqrt{ }$ \\
\hline \multicolumn{2}{|c|}{ Unit Usaha Mitra } \\
\hline Aksebilitas & $\sqrt{ }$ \\
\hline Konten & $\sqrt{ }$ \\
\hline Transaksi & $\sqrt{ }$ \\
\hline \multicolumn{2}{|c|}{ Sumber: data diolah } \\
\hline \multicolumn{2}{|l|}{ 4.5 Diseminasi } \\
\hline \multicolumn{2}{|c|}{ Release awal model melalui website. } \\
\hline \multicolumn{2}{|c|}{$\begin{array}{l}\text { Merupakan tahap dimana mulai } \\
\text { diterapkannya platform "Nobel Gadde2 } \\
\text { Na" yang dapat diakses di https://gadde.id } \\
\text { atau http://gadde.nobel.ac.id. }\end{array}$} \\
\hline
\end{tabular}


Disaat yang sama dilakukan proses alih teknologi kepada pengelola inkubator bisnis berupa pelatihan dan pembuatan panduan operasional serta perawatan sistem. Untuk selanjutnya, aplikasi dikendalikan oleh Pengelola Inkubator Bisnis STIE Nobel Indonesia Makassar.

\section{SIMPULAN DAN SARAN}

Platform "Nobel Gadde2 Na" merupakan aplikasi yang mewadahi inkubator bisnis STIE Nobel Indonesia. Sebagai wadah untuk sosialisasi usahausaha STIE Nobel Indonesia, mahasiswa/i dan mitra/masyarakat sekitarnya agar dikenal lebih luas. Selain dapat mempersiapkan peserta didik mengenal dunia usaha sejak dini, juga sebagai sarana pengabdian masyarakat yang nantinya membentuk jaringan usaha dalam Akademic Entrepreneurship.

Platform ini dapat dikembangkan lagi menjadi sebuah marketplace dengan cakupan yang lebih luas. Juga penerapan Financial Technology (Fintech) di dalamnya.

\section{DAFTAR PUSTAKA}

Abidah, K. N., Baihaqi, I., \& Persada, S. F. (2020). Konsep Model Bisnis Inkubasi Online dengan Perspektif Triple Helix. Jurnal Teknik ITS, 9(1), A13-A18.

https://doi.org/10.12962/j23373539.v9 i1.42551

Agunawan. (2020). Pembelajaran Vokasi di Perguruan Tinggi-Tinjauan Filsafat dan Rekonstruksi Teori. Nobel Press Makassar.
Ardiansyah, M., Latifah, N., \& Widayani, A. (2019). Peranan Inkubator Bisnis dalam Menumbuhkan Jiwa Kewirausahaan Mahasiswa Akademi Komunitas Negeri Putra Sang Fajar Blitar. VOCATECH: Vocational Education and Technology Journal, 1(1), 51-56. https://doi.org/10.38038/vocatech.v1i0 .11

B. Urban. (2019). Academic Entrepreneurship: A Focus On Entrepreneurial Alertness, Attitudes, Norms and Beliefs. South African Journal of Higher Education, 33, 192-204.

http://dx.doi.org/10.20853/33-3-2800

Borg and Gall. (1983). Educational Research: An Introduction. New York and London: Logman.

Dr. Budiyono Saputro, M.Pd. (2017). Manajemen Penelitian Pengembangan (Vol. 1). Aswaja Pressindo.

Fitriany, F., Ridwan, Maryadi, \& Muh. Saleh R. (2019). Implementasi Program Pengembangan Kewirausahaan STIE Nobel Indonesia Tahun 2018. CARADDE: Jurnal Pengabdian Kepada Masyarakat, 1(2), 124-130. https://doi.org/10.31960/caradde.v1i2. 27

Lutfiani, N., Rahardja, U., \& Manik, I. S. P. (2020). Peran Inkubator Bisnis dalam Membangun Startup pada Perguruan Tinggi. Jurnal Penelitan Ekonomi Dan Bisnis, 5(1), 77-89. https://doi.org/10.33633/jpeb.v5i1.272 7

Media, K. C. (2020, September 22). Atasi Gap Tenaga Kerja, Transformasi Pendidikan Vokasi Jadi Hal Penting. KOMPAS.com. 
https://edukasi.kompas.com/read/2020

/09/22/172600071/atasi-gap-tenaga-

kerja-transformasi-pendidikan-vokasijadi-hal-penting

Ristekbrin. (2018, December 3). Buka

Forum IBT, Menristekdikti Akan

Dorong Inkubasi Bisnis Teknologi di

Perguruan Tinggi - Kemenristek /

BRIN. Menristekdikti.

https://www.ristekbrin.go.id/buka-

forum-ibt-menristekdikti-akan-

dorong-inkubasi-bisnis-teknologi-di-

perguruan-tinggi/

Roger S. Pressman, R. S. (2010). Software

Engineering: A Practitioner's

Approach. 161.

Sugiyono. (2012). Metode Penelitian

Kuantitatif, Kualitatif, dan $R \& D$.

Alfabeta-Bandung. 